\title{
Satellites beam in biomass estimates
}

\author{
Additional detail could help bring woodland into a future climate treaty.
}

Whatever agreement emerges from the climate meeting in Copenhagen, many expect that it will include a mechanism allowing rich nations to offset their emissions by paying poorer countries to protect their forests - and the carbon they contain. But just how much carbon is at stake? Researchers at the meeting have given their best answer yet: the first satellite-based estimates of the biomass contained in the world's tropical forests.

Current biomass estimates for the tropics are based on data gathered by the Food and Agriculture Organization of the United Nations (FAO), and their quality varies greatly from country to country. As a result, baseline figures for biomass are some of the biggest uncertainties in calculating emissions from deforestation and forest degradation, recently estimated to be around 15\% of global carbon emissions (G. R. van der Werf et al. Nature Geosci. 2, 737-738; 2009).

The latest assessments, presented at Copenhagen, harness data from multiple satellites as well as thousands of ground plots, and should help governments and other scientists to estimate how much carbon is locked within trees, vegetation and soils on a given patch of land rather than relying on rough averages that are calculated across a forest.

Sassan Saatchi, an environmental scientist at NASA's Jet Propulsion Laboratory in Pasadena, California, worked on one study with researchers at the carbon consulting firm Winrock International in Arlington, Virginia. He says that their preliminary calculations (see map) accord well with previous estimates. South America comes in with about 145 gigatonnes of carbon in vegetation and soils, about $26 \%$ higher than what has been reported by the Intergovernmental Panel on Climate Change (IPCC). The figures for Africa (51 gigatonnes) and south Asia (46 gigatonnes) are about the same as the IPCC figures.

\section{A question of scale}

But Saatchi says that the study provides additional information about biomass levels at regional and national levels. "You cannot really nail down this problem unless you have the distribution," he says. "You need to know how biomass is distributed and how it's changing over time, almost everywhere, with some resolution and accuracy."
Funded in part by the World Bank, the work provides a snapshot at 1-kilometre resolution of tropical forests as they were in 2000, when most of the satellite data were collected, as well as more recent deforestation trends.

Also at Copenhagen, researchers at the Woods Hole Research Center in Massachusetts presented another pan-tropical biomass assessment, which had a resolution of 500 metres. Like the Winrock study, it includes spectral data from NASA satellites as well as laser measurements of forest canopy height from an instrument on NASA's Ice, Cloud, and land Elevation Satellite (ICESat) that was designed to study polar ice caps. The two teams have yet to compare results.

Richard Houghton, a biomass expert at Woods Hole, says that it is good news that mul-

\section{THE WORLD'S CARBON STORES}

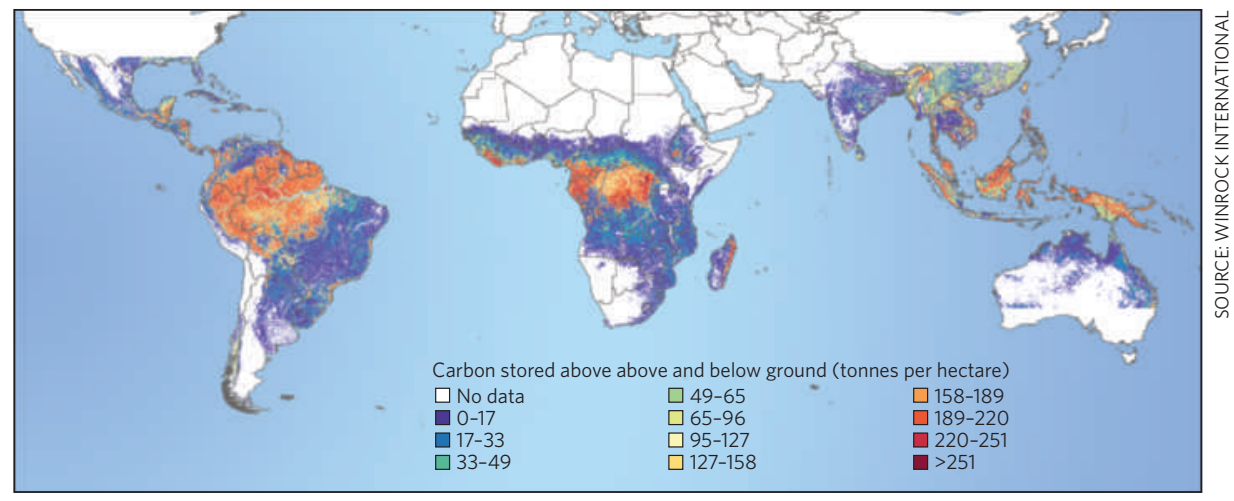

\section{UK research funding proposal is 'irresponsible'}

Efforts to judge science on its practical returns often raise hackles, and Britain's latest plan is no exception. Some of the nation's leading universities have condemned a scheme that would assess the economic and social benefits of research to help determine who wins a large fraction of university funding, and more than 12,000 academics have signed a petition opposing the plan. The public consultation on the proposals closed this week.

Concerns first arose in September, when the Higher
Education Funding Council for England (HEFCE) launched its proposals for the Research Excellence Framework (REF), the successor to the Research Assessment Exercise (RAE) used to divide more than $E 1.5$ billion (US $\$ 2.4$ billion) per year in public funds between universities. Whereas the RAE did not use impact criteria, the REF, due to begin in 2013 , will require researchers to submit case studies detailing examples of the societal and economic benefits of their research from the past 10-15 years. These examples would help to determine the fate of almost a third of the funding. The overall aim is to make explicit how much benefit the British taxpayer gets from funding research.

Ian Leslie, pro-vice chancellor for research at the University of Cambridge, considers the proposals "neither credible nor responsible". He says that the university recognizes that research institutions need to communicate the impact of the research they undertake. But HEFCE's proposals would turn "first-rate universities into second-rate companies", he says, adding that it is "irresponsible" to apportion so much funding on the basis of the impact of the research.

Similar requirements in the United States encourage some researchers to "oversell" the potential impact of their work, says William Schowalter, a chemical engineer from Princeton University, New Jersey, who was an international judge in the final RAE in 2008. This can skew funding towards fields such as nanotechnology that promise more immediate benefits.

Peter Knight, deputy rector for 
tiple teams are tackling the big-picture question of tropical forest biomass. "We need a couple of independent estimates just to see how well they match," he says. "Anybody can make a map. If they differ, at least it identifies the areas that need further analysis."

The next step, says Alexander Lotsch, a geographer at the World Bank in Washington DC, is to produce better estimates for carbon emissions from deforestation. $\mathrm{He}$ adds that Saatchi's research is still a "work in progress".

Satellites can reliably track deforestation and, increasingly, small-scale logging. In Copenhagen, Greg Asner of the Carnegie Institution of Science in Stanford, California, and Google.org unveiled an online tool that allows tropical countries, beginning in South America, to map deforestation using an automated system to analyse satellite imagery. Asner has also developed a system for assessing biomass at finer resolution, which will be necessary if forests are going to be linked to international carbon markets.

The new pan-tropical biomass maps from Saatchi and Woods Hole won't accomplish that goal, but they can provide scientists and policy-makers with a better understanding of carbon trends. For example, using a similar technique to Saatchi, Asner has found that deforestation in Brazil is moving into higher biomass areas in the interior of the forest. That suggests that emissions will probably rise over time on a per-hectare basis, offsetting some of the reductions in deforestation that Brazil aims to achieve in the coming decade (see Nature doi:10.1038/ news.2009.752; 2009).

Jeff Tollefson

See also www.nature.com/roadtocopenhagen

research at Imperial College London, says that he wants to delay the REF by a year to incorporate the findings of planned pilot trials. He recommends that just $15-20 \%$ of the audit be devoted to impact assessment, whereas the University and College Union, a trade union for academics, would like the impact component to be removed.

David Price, vice-provost for research at University College London, says that any assessment of impact should include benefit to the academic community, and not just the economy and society as currently proposed, to ensure that fields such as mathematics and social sciences are not disadvantaged.

HEFCE will publish a summary of the responses to the consultation, and its plans for the REF, in spring 2010.

Natasha Gilbert

\section{Hope for Japan's key projects}

When Japan's government changed hands in September for the first time in five decades, many Japanese people hoped that the newly powerful Democratic Party of Japan would revitalize their country. But the new government has since sent scientists on an emotional rollercoaster. In recent weeks, two cabinet-level bodies, both chaired by Prime Minister Yukio Hatoyama, have recommended drastically different financial futures for major scientific projects.

One set of proposals, from the Government Revitalization Unit (GRU) that was set up in September to trim bureaucratic fat, recommends deep cuts for many key projects. These include a proposed next-generation supercomputer, the SPring- 8 synchrotron in Harima, and Earth-science research. Scientists protested against those cuts (see Nature 462, 557; 2009). But last week came news of a separate recommendation from the Council for Science and Technology Policy (CSTP), Japan's highest science-policy-making body, proposing continued support for those projects and many others.

For instance, the SPring-8 synchrotron and the Global Center of Excellence programmes - meant to strengthen doctoral research programmes - had each been headed for cuts of one-third or more, but the CSTP says they should be "prioritized and given the necessary resources". The nextgeneration supercomputer, which could have faced outright termination, should also be supported, it says.

In Japan, where government decisions are usually made in bureaucratic back rooms and handed out as a harmonious consensus, the apparent contradiction is baffling researchers. "The decision-making process is unclear," says Tadashi Watanabe, project leader for the supercomputer. "It is very unsettling."

Final budget decisions will be made later this month, but the prime minister has called the CSTP proposals "valuable opinions", and said that he would "work to ensure they were reflected in the final budget". Many think Hatoyama could be leaning towards accepting the CSTP's recommendations, perhaps because of the outcry over the proposed cuts. "It's too early to tell, but you can safely say that the top leadership did recognize the problem," says Atsushi Sunami, a sciencepolicy expert at the National Graduate

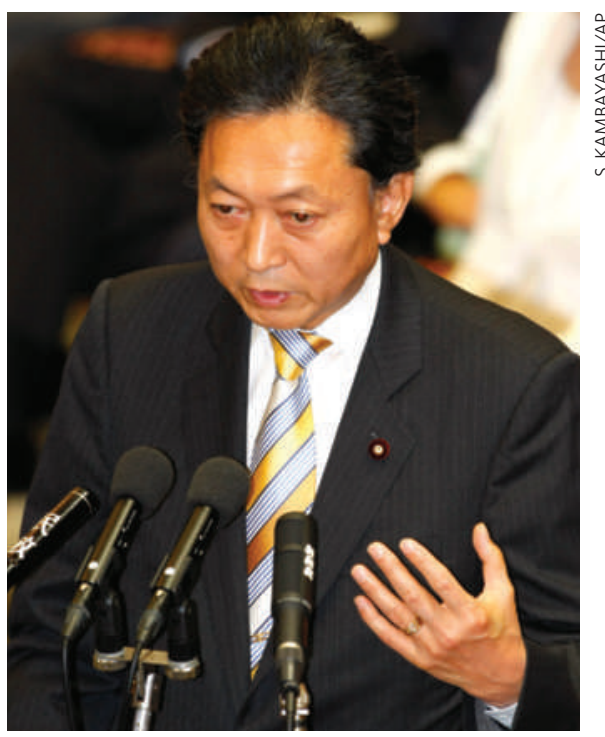

Scientists are hoping that Japan's prime minister Yukio Hatoyama will avert proposed funding cuts.

Institute for Policy Studies in Tokyo.

The GRU was earlier criticized by scientists for recommending cuts without obtaining sufficient external input; projects were usually explained to the decisionmaking committee in a one-hour session by a bureaucrat. According to the Japanese media last week, the GRU plans to reopen debate on the supercomputer project in a public forum that will involve many scientists.

For researchers, the near demise of beloved projects has been a wake-up call to the need to justify them to the public as well as to bureaucrats and external evaluators. Last week, leaders of the supercomputer project posted on their website a list of frequently asked questions on the project's significance, including: "What is great about the supercomputer?"

Watanabe says the team doesn't yet have a long-term strategy for engaging the public, but he wants to emphasize that the supercomputer would have a major role in Japan's main research fields, including nanoscience, life science and environmental science. "We have to get that point across," he says.

Sunami agrees that scientists in Japan can't take public support for granted. "Even if the budget for the supercomputer and SPring-8 are saved at a smaller scale," he says, "they have to engage with the public more." David Cyranoski 